\title{
Convex-hull mass estimates of the dodo (Raphus cucullatus): application of a CT-based mass estimation technique
}

Charlotte A Brassey, Thomas G O'Mahoney, Andrew C Kitchener, Phillip L Manning, William I Sellers

The external appearance of the dodo (Raphus cucullatus, Linnaeus, 1758) has been a source of considerable intrigue as contemporaneous accounts or depictions are rare. The body mass of the dodo has been particularly contentious, with the flightless pigeon alternatively reconstructed as slim or fat depending upon the skeletal metric used as the basis for mass prediction. Resolving this dichotomy and obtaining a reliable estimate for mass is essential before future analyses regarding dodo life history, physiology or biomechanics can be conducted. Previous mass estimates of the dodo have relied upon predictive equations based upon hind limb dimensions of extant pigeons. Yet the hind limb proportions of dodo have been found to differ considerably from those of their modern relatives, particularly with regards to midshaft diameter. Therefore, application of predictive equations to unusually robust fossil skeletal elements may bias mass estimates. We present a whole-body computed tomography (CT) -based mass estimation technique for application to the dodo. We generate 3D volumetric renders of the articulated skeletons of 20 species of extant pigeons, and wrap minimum-fit 'convex hulls' around their bony extremities. Convex hull volume is subsequently regressed against mass to generate predictive models based upon whole skeletons. Our best-performing predictive model is characterized by high correlation coefficients and low mean squared error $(a=-$ 2.31, $\left.b=0.90, r^{2}=0.97, \mathrm{MSE}=0.0046\right)$. When applied to articulated composite skeletons of the dodo (National Museums Scotland, NMS.Z.1993.13; Natural History Museum, NHMUK A.9040 and S/1988.50.1), we estimate eviscerated body masses of 8-10.8 kg. When accounting for missing soft tissues, this may equate to live masses of $10.6-14.3 \mathrm{~kg}$. Mass predictions presented here overlap at the lower end of those previously published, and support recent suggestions of a relatively slim dodo. CT-based reconstructions provide a means of objectively estimating mass and body segment properties of extinct species using whole articulated skeletons. 
1 Convex-hull mass estimates of the dodo (Raphus cucullatus): application of a CTbased mass estimation technique

4 Brassey, C.A. ${ }^{1 *}$, O’Mahoney, T. ${ }^{1}$, Kitchener, A.C. ${ }^{2,3}$, Manning, P. L. ${ }^{4,5}$, Sellers, W.I. ${ }^{1}$

${ }^{1}$ Faculty of Life Sciences, University of Manchester, Manchester M13 9PL

$7 \quad{ }^{2}$ Department of Natural Sciences, National Museums Scotland, Edinburgh EH1 1JF

${ }^{3}$ Institute of Geography, School of Geosciences, University of Edinburgh, Drummond Street, Edinburgh, EH8 9XP

${ }^{4}$ Interdisciplinary Centre for Ancient Life, School of Earth, Atmospheric and Environmental Sciences, University of Manchester, Manchester M13 9PL

${ }^{5}$ Department of Geology and Environmental Geosciences, College of Charleston, Charleston, South Carolina, United States of America *corresponding author (charlotte.brassey@manchester.ac.uk) 


\section{Abstract}

17 The external appearance of the dodo (Raphus cucullatus, Linnaeus, 1758) has been a

18 source of considerable intrigue as trustworthy contemporaneous accounts or depictions

19 are rare. The body mass of the dodo has been particularly contentious, with this

20 flightless pigeon alternatively reconstructed as slim or fat depending upon the pictorial

21 evidence or skeletal metric used as the basis for mass prediction. Resolving this

22 dichotomy and obtaining a reliable estimate for mass is essential before future analyses

23 regarding dodo life history, physiology or biomechanics can be conducted.

25 Previous mass estimates of the dodo have relied upon predictive equations based upon 26 hind limb dimensions of extant pigeons. Yet the hind limb proportions of dodo have 27 been found to differ considerably from those of their modern relatives, particularly with 28 regards to midshaft diameter. Therefore, application of predictive equations to unusually 29 robust fossil skeletal elements may bias mass estimates. We present a whole-body 30 computed tomography (CT) -based mass estimation technique for application to the

31 dodo. We generate 3D volumetric renders of the articulated skeletons of 20 species of 32 extant pigeons, and wrap minimum-fit 'convex hulls' around their bony extremities.

33 Convex hull volume is subsequently regressed against mass to generate predictive 34 models based upon whole skeletons.

36 Our best-performing predictive model is characterized by high correlation coefficients

37 and low mean squared error $\left(a=-2.31, b=0.90, r^{2}=0.97, \mathrm{MSE}=0.0046\right)$. When applied to 38 articulated composite skeletons of the dodo (National Museums Scotland, 
39 NMS.Z.1993.13; Natural History Museum, NHMUK A.9040 and S/1988.50.1), we

40 estimate eviscerated body masses of $8-10.8 \mathrm{~kg}$. When accounting for missing soft

41 tissues, this may equate to live masses of $10.6-14.3 \mathrm{~kg}$. Mass predictions presented

42 here overlap at the lower end of those previously published, and support recent

43 suggestions of a relatively slim dodo. CT-based reconstructions provide a means of

44 objectively estimating mass and body segment properties of extinct species using whole 45 articulated skeletons.

46 


\section{Introduction}

48 Body mass $\left(M_{\mathrm{b}}\right)$ is a fundamental descriptor of an organism and co-varies with

49 important ecological and physiological traits, such as population density, metabolism

50 and cost-of-transport [1]. Key evolutionary scenarios, such as the origin of avian flight

51 [2] and the extinction of island flightless avian species [3], have been diagnosed on the

52 basis of estimated $M_{\mathrm{b}}$. Therefore, the reconstruction of body mass in extinct bird

53 species is a subject of considerable interest within the palaeontological and evolutionary

54 biology literature [2-6].

An often-applied technique for estimating the body mass of an extinct vertebrate has

57 been to measure a skeletal dimension from modern species, such as femur

58 circumference [7] or glenoid diameter [8], and apply this as the independent variable in

59 a regression against body mass. However, 'overdevelopment' of the pelvic apparatus

60 has been found to be significantly correlated with the flightless condition in extant birds

61 [9]. Therefore, the application of mass prediction equations, based solely on hind limb

62 material of flightless avian taxa, has been questioned in extinct species such as the 63 moa [6].

65 The dodo (Raphus cucullatus, Linnaeus, 1758 [10]) is an iconic representative of island

66 flightlessness and human-induced extinction, and its external appearance has been a 67 source of considerable intrigue due to the scarcity of trustworthy contemporaneous 68 accounts or depictions [11]. This extinct flightless columbiform was endemic to the 69 island of Mauritius. However, the skeletal anatomy of the dodo is comparatively well 
70 known, and its pelvic morphology has been thoroughly investigated. Hind limb bones of

71 R. cucullatus have been found to differ considerably in both their length and width

72 relative to their volant relatives [11, although see 12]. Yet previous attempts to estimate

73 the body mass of the dodo have predominantly relied upon predictive equations derived

74 solely from the hind limb metrics of extant species [14-16].

75 An alternative approach to mass estimation involves the reconstruction of 3D volumetric 76 models. An early volumetric reconstruction of the dodo was conducted by physically

77 sculpting a scale model of an individual and estimating volume via fluid displacement 78 [13]. Whilst such volumetric techniques are less liable to bias by individual robust/gracile postcranial elements than traditional linear bivariate equations, they do inevitably

80 involve some degree of artistic licence in the sculpting of soft tissue contours and 81 require an estimate for fossil body density to be assigned.

82 Following advances in 3D imaging technology, the use of digital skeletal models in 83 mass estimation of fossil skeletons has become increasingly popular [17-20]. These 84 studies typically involve the 'wrapping' of geometric shapes or lofted smooth surfaces 85 around the skeleton in order to replicate the original soft tissue contour of the animal. 86 Zero-density cavities such as lung and tracheal space may also be modeled [21]. 87 However, similar to physical sculpting with clay, assumptions must still be made 88 regarding body density and the extent of soft tissues beyond the skeleton. Therefore, it 89 is essential that reconstructions are grounded within a quantitative understanding of

90 extant species in order to avoid subjective modeling of soft tissues (both body and 91 plumage). 
92 Here we present new mass estimates for the dodo based on an alternative 'convex hull'

93 volumetric reconstruction approach $[22,23]$. The convex hull $(\mathrm{CH})$ of a set of points is

94 defined as the smallest convex polytope that contains all said points, and intuitively can

95 be thought of as a shrink-wrap fit around an object (see Figure 1). Application of the

96 convex hulling technique to mass estimation does not involve any subjective

97 reconstruction of soft tissue anatomy and solely relies upon the underlying skeleton. We

98 calculate minimum convex hull volumes for a sample of composite articulated dodo

99 skeletons, and convert these to body mass estimates using a computed tomography

100 (CT) calibration dataset of 20 species of extant pigeon. To our knowledge, this is the

101 first time such an extensive CT dataset of extant animals has been used to reconstruct

102 the body mass of a fossil of an extinct species. 


\section{Methods and Materials}

104 The modern dataset consists of 20 columbiform individuals, spanning a wide variety of

105 body sizes from a $70 \mathrm{~g}$ fruit dove (Ptilinopus; Swainson, 1825 [24]) up to the largest

106 extant pigeon, the $2 \mathrm{~kg}$ Victoria crowned pigeon (Goura victoria; Fraser, 1844 [25]). We

107 also cover a broad taxonomic range (including the closest extant relative of the dodo

108 [26], the Nicobar pigeon (Caloenas nicobarica; Linnaeus, 1758 [10])). Frozen carcasses

109 were sourced from National Museums Scotland, Edinburgh, and the University of

110 Manchester (see Table 1). Carcasses were CT scanned at Leahurst Veterinary School,

111 University of Liverpool, in a Toshiba Aquilion PRIME helical scanner at a slice thickness

112 of $0.5 \mathrm{~mm}$ and a pixel spacing of between $0.24-0.51 \mathrm{~mm}$, depending on the maximum

113 size of the specimen. 3D models of the skeletons were generated in Seg3D [27], using

114 an automatic threshold with subsequent manual masking to remove the dense rachises

115 attached to the forelimb.

116

117 Models were exported into Geomagic Studio (www.geomagic.com), where each

118 skeleton was divided into functional units (skull, neck, trunk, humerus, radius+ulna,

119 carpometacarpals, femur, tibiotarsus+fibula, tarsometatarsus, feet). The cervical series

120 was further subdivided in order to achieve a tight-fitting hull around the curving neck.

121 Minimum convex hulls were calculated in MATLAB (www.mathworks.com), using the

122 'convhull' function implementing the Quickhull (qhull) algorithm [28], and total convex

123 hull volume was calculated as the sum of individual segment volumes (see Figure 1).

124 Body mass was measured for each carcass, and the relationship between $M_{\mathrm{b}}$ and 
125 convex hull volume $\left(\mathrm{CH}_{\text {vol }}\right)$ was estimated using ordinary least squares (OLS)

126 regression on $\log _{10}$ transformed data. As the purpose of the regression was to derive a

127 predictive equation, a type-I regression, such as OLS, was deemed most appropriate

128 [29]. Additionally we accounted for the statistical non-independence of phylogenetically-

129 related data points by carrying out phylogenetic generalized least squares (PGLS)

130 regressions, implemented in MATLAB using 'Regression2' software [30]. A majority-rule

131 consensus tree was calculated using the R package 'ape' [31] based upon a sample of

13210,000 trees sourced from the birdtree.org website [32] using the Hackett et al. [33]

133 phylogeny as a backbone. All branch lengths were set to 1 .

135 To reconstruct the body masses of articulated dodo skeletons, we generated 3D digital

136 models of these specimens. It must be highlighted here that all dodo skeletons included

137 in the present study are composites, likely comprising different individuals of varying

138 age and/or sex (see below for further discussion. The Edinburgh dodo (National

139 Museums Scotland, NMS.Z.1993.13) was scanned using a Z+F Imager 5010 LiDAR

140 (Light Detection And Range) scanner and reconstructed in the $\mathrm{Z}+\mathrm{F}$ LaserControl

141 software. The Natural History Museum (NHMUK), London specimens (Tring skeleton,

142 S/1988.50.1; South Kensington specimen NHM A9040) were digitized using the

143 photogrammetric technique detailed elsewhere $[34,35]$ and reconstructed in VisualSFM

144 [36]. Despite application of two alternative imaging techniques, previous studies have

145 found the results obtained via photogrammetry and laser scanning to be comparable

146 [34], and convex hull results to be insensitive to point cloud density [23,37]. 3D models

147 of the dodo skeletons were cleaned up in Geomagic and subdivided into functional 
148 units. Our only intervention with the dodo models was to mirror the right hand side of the

149 Edinburgh ribcage to account for missing ribs on its left side. Convex hulls were fitted

150 according to the methodology applied to modern pigeons.

151 The largest extant pigeon (G. victoria) weighs on average $2.3 \mathrm{~kg}$ [38], a value far below

152 all previous estimates of dodo mass. When applying a pigeon-based equation to predict

153 dodo body mass, it is therefore necessary to extrapolate beyond the body size range

154 upon which the predictive model is based. By restricting ourselves to phylogenetically

155 closely related species, the fossil species of interest may therefore be up to an order of

156 magnitude greater in size than any extant relative. Furthermore the majority of modern

157 pigeons included in this dataset are proficient fliers and have likely been subject to very

158 different evolutionary pressures than the flightless dodo.

159 For this reason, we also applied a previously published convex hull equation derived

160 from extant ratites and galloanserae birds, extending the range of body masses beyond

$16160 \mathrm{~kg}$ and incorporating ground-dwelling species. Raw data are taken from Brassey et

162 al [23], whilst the axes have been inverted $\left(\log _{10}\right.$ volume as the independent variable vs.

$163 \log _{10}$ mass as the dependent variable) to create a predictive model. Standard OLS

164 regression was preferred as previous analyses found uncorrected type-I models to fit

165 the data better than phylogenetically corrected regressions [23]. It must be emphasized

166 that the non-pigeon data are derived from an earlier study applying a different imaging

167 technique (light detection and range, LiDAR, on museum mounted skeletons) and uses

168 literature-assigned values for mass due to lack of associated body masses. Whilst the

169 previous study found no significant impact on calculated $\mathrm{CH}_{\text {vol }}$ due to variation in point

170 cloud density associated with different imaging techniques, caution should be exercised 
171 when comparing the regression models. 


\section{Results}

173 Total convex hull volumes for the modern pigeons are reported in Table 1 , and

174 segment-specific $\mathrm{CH}_{\text {vol }}$ values can be found in Supplementary Material S1. Convex hull

175 models are available for download from http://www.animalsimulation.org. We found

176 considerable variation between frozen pigeon specimens in the posture of the digits

177 forming the foot i.e. adduction vs. abduction of the digits. This influenced the overall

178 shape, and hence calculated $\mathrm{CH}_{\text {vol }}$, of the foot functional units (see Figure 1D). Given

179 repositioning of the skeleton was not possible due to the frozen nature of the carcasses,

180 here we report total $\mathrm{CH}_{\text {vol }}$ values with and without feet included. External inspection of

181 the carcasses suggested evisceration had been carried out on some specimens. Using

182 CT scans the occurrence of evisceration was confirmed across our modern dataset (see

183 Table 1). Therefore, we report separate predictive models derived from 'eviscerated'

184 carcasses $(n=13)$, 'intact' carcasses $(n=7)$, and a third 'combined' model comprising

185 both eviscerated and intact specimens $(n=20)$.

186

187 The results of the OLS regression analyses are presented in Table 2, and

188 phylogenetically corrected (PGLS) regressions are given in Supplementary Material S2

189 alongside the composite phylogeny used in this analysis. PGLS regressions did not

190 provide a better fit to the data than uncorrected OLS regressions (as determined by

191 Akaike Information Criterion values, AIC) for the 'eviscerated' and 'combined' models

192 (Table 2). However, a PGLS model was found to fit the 'intact' extant pigeon data better

193 than an uncorrected OLS model (Table 2). 
195 Removing $\mathrm{CH}_{\text {vol }}$ of the feet from the analyses had very little effect on the results of the

196 regression, although mean squared error (MSE) decreased slightly in all models and

197 therefore only regression models minus feet are discussed any further in the text. Figure

1982 illustrates a strong positive correlation between $M_{\mathrm{b}}$ and $\mathrm{CH}_{\text {vol }}$ for the eviscerated

199 specimens within the sample $\left(a=-2.31, b=0.90, r^{2}=0.97\right)$. In contrast, the relationship

200 between $M_{\mathrm{b}}$ and $\mathrm{CH}_{\text {vol }}$ in intact specimens illustrates a weak positive correlation

201 characterized by low correlation coefficients and high mean square error $(a=-1.06$,

$\left.202 b=0.66, r^{2}=0.70\right)$. Intact specimens do not plot consistently above the eviscerated

203 pigeon slope (Figure 2) and are instead characterized by a high degree of scatter.

204 When combining the eviscerated and intact specimens into one dataset, $\mathrm{M}_{\mathrm{b}}$ and $\mathrm{CH}_{\mathrm{vol}}$

205 remain tightly correlated $\left(a=-2.08, b=0.85, r^{2}=0.92\right)$.

206

207 Total $\mathrm{CH}_{\text {vol }}$ calculated for the mounted dodo skeletons are reported in Table 3 (see

208 Supplementary Material S3 for segment-specific values) and an example of a

209 photogrammetric model is illustrated in Figure 3. Using the 'eviscerated' predictive

210 model, dressed $M_{\mathrm{b}}$ is estimated as $8.0 \mathrm{~kg}$ (95\% prediction interval $(\mathrm{PI}) 4.6-13.9 \mathrm{~kg}$ ), 8.7

$211 \mathrm{~kg}(95 \% \mathrm{PI} 5.0-15.0 \mathrm{~kg})$ and $10.8 \mathrm{~kg}(95 \% \mathrm{PI} 6.1-19.0 \mathrm{~kg})$ respectively for the NHMUK

212 Tring, NHMUK South Kensington and Edinburgh dodos. Applying the 'combined'

213 predictive equation results in wider and therefore more conservative prediction intervals

214 (NHMUK Tring, 6.7 kg 95\%PI 3.5-13.1 kg; NHMUK South Kensington, 7.3 kg 95\%PI

$215 \quad 3.7-14.3 \mathrm{~kg}$; Edinburgh, $9.0 \mathrm{~kg}$ 95\%PI 4.5-17.9 kg).

216 
217 The results of the OLS regression of convex hull volume against body mass for a

218 dataset of ground-dwelling ratites and galloanserae derived from Brassey et al [23] are

219 presented in Table 2. This relationship is also characterized by high correlation

220 coefficients $\left(a=-1.65, b=0.82, r^{2}=0.97\right)$, and results in intact mass estimates of $10.9 \mathrm{~kg}$

221 (95\%PI 5.7-20.6 kg), $11.6 \mathrm{~kg}(95 \% \mathrm{Pl}$ 6.1-22.1 kg) and $14.0 \mathrm{~kg}(95 \% \mathrm{Pl}$ 7.3-26.6 kg)

222 respectively for the NHMUK Tring, NHMUK South Kensington and Edinburgh dodos.

223

224 Figure 4 illustrates the distribution of segment-specific convex hull volumes as a 225 proportion of total $\mathrm{CH}_{\text {vol }}$ within the models. In extant pigeons trunk $\mathrm{CH}_{\text {vol }}$ represents on 226 average $69 \%$ of total $\mathrm{CH}_{\text {vol. }}$. The NHMUK Tring dodo skeleton has a percentage trunk 227 volume significantly lower than that of extant pigeons (67\%, 1 -tailed $t$-test, $t=3.23$, $228 p<0.01$ ), whilst percentage trunk volume in the NHMUK South Kensington and 229 Edinburgh skeletons is significantly higher than extant pigeons $(71 \%$ and $80 \%, t=-2.23$ 230 and -13.0 respectively, $p<0.05)$. With the exception of the tarsometatarsii of the NHMUK

231 South Kensington skeleton, pelvic convex hull segments of the dodos comprise a 232 significantly greater proportion of total $\mathrm{CH}_{\text {vol }}$ than in extant pigeons $(p<0.05)$. In contrast, 233 dodo pectoral convex hull segments contribute proportionally less to total $\mathrm{CH}_{\text {vol }}$ than in 234 extant pigeons $(p<0.0001)$ (Figure 4$)$. 


\section{Discussion}

\section{Predictive equation derived from modern CT dataset}

237 To our knowledge the present study represents the first application of a predictive

238 equation derived solely from whole-body CT to the problem of body mass estimation for

239 extinct animals. Previous volumetric mass estimate studies have relied upon articulated

240 museum skeletons of extant species to derive a calibration equation [6,22]. Yet

241 articulated skeletons are often missing crucial specimen information, such as a

242 recorded body mass. By working with frozen carcasses, body mass is directly

243 measurable and uncertainties associated with mounting and posing of the skeletons can

244 be avoided [23].

246 Our dataset consists of both 'intact' and 'eviscerated' pigeons as determined by

247 examination of CT scans. Previous analyses of carcass composition have found

248 eviscerated mass to represent $62-66 \%$ of live body mass in rock doves $[39,40]$, yet no

249 data exist regarding the possible scaling of internal organ mass across a range of body

250 sizes in the Columbiformes. As can be seen in Figure 2, there is no consistent disparity

251 between intact and eviscerated specimens, and the relationship between $M_{\mathrm{b}}$ and $C H_{\text {vol }}$

252 in intact pigeons is relatively weak $\left(r^{2}=70, p=0.019\right)$. This correlation improves

253 considerably when accounting for phylogeny (Supplementary Material S2), but remains

254 weaker than the relationship between $M_{\mathrm{b}}$ and $C H_{\mathrm{vol}}$ characterizing eviscerated

255 specimens. Live body mass has been shown to vary considerably in wild animals due to

256 hydration, nutrition and gut content [41] and therefore some degree of scatter is to be 
257 expected in intact carcasses. Particularly striking is the variability in gizzard contents

258 between similar-sized specimens visible in CT scans (see Figure 5).

260 This suggests intact pigeon $M_{\mathrm{b}}$ cannot be corrected for the presence of internal organs

261 using a single factor representing average percentage eviscerated mass as a function

262 of live mass (i.e. multiplying by values of 0.62 or 0.66 previously found in the literature).

263 Additionally, attempting to correct intact $M_{\mathrm{b}}$ by substituting intact $\mathrm{CH}_{\text {vol }}$ into the

264 eviscerated regression model would be highly circular and result in artificially inflated

265 correlation coefficients, if the equation were used in a predictive capacity. Therefore, we

266 apply both the uncorrected OLS eviscerated model and combined (eviscerated and

267 intact) model to bracket the range of likely dodo body masses. Interestingly, the very

268 high correlation coefficient and low mean squared error of the eviscerated equation

269 suggest that once the variability associated with fluid and gut content is removed, the

270 relationship between the mass of the remaining musculoskeletal system and $\mathrm{CH}_{\mathrm{vol}}$ is

271 more tightly constrained.

272

273 Volumetric body mass estimation applied to the dodo

274 No reliable records of the body mass of dodo exist prior to its extinction in the $17^{\text {th }}$

275 Century and subsequent mass estimates have varied considerably. Early accounts of

276 the flightless bird suggested an average mass of $50 \mathrm{lb}(22 \mathrm{~kg})$ [42], although such

277 accounts "have a tendency towards exaggeration" [11]. More recently a 'slim' dodo

278 (mean $10.2 \mathrm{~kg}$ ) was proposed on the basis of femoral, tibiotarsal and tarsometatarsal

279 length scaling in modern birds [14]. However hind limb bone length has been shown to 
280 correlate poorly with body mass relative to other cross-sectional geometric properties

281 and frequently contains a strong functional signal [8,43-45]. Alternatively, a predictive

282 equation based on femoral and tibiotarsal least circumference in ground-dwelling birds

283 has suggested mass estimates between $9.5-12.3 \mathrm{~kg}[15]$.

284

285 The application of volumetric mass estimation techniques to the dodo has been rare. A 286 sculpted scale model of a 'slim' dodo based upon mean skeletal measures was created

287 to replicate sketches dating contemporaneously to its survival on Mauritius and resulted 288 in mass estimated of $12.5-16.1 \mathrm{~kg}$ [13]. In the same study a 'fat' dodo model based on 289 later 'exaggerated' artworks was predicted to weigh between $21.7-27.8 \mathrm{~kg}$.

290

291 Here we estimate mean eviscerated body masses for articulated composite dodo 292 skeletons of between 8.0-10.8 kg. Without further information regarding the effect of 293 within-subject variability in gizzard, crop or gut content or interspecific scaling of viscera 294 mass, any extrapolation to a live mass should be treated with caution. However, with 295 this caveat in mind, a $33 \%$ increase in mass to account for missing organs (as 296 quantified in extant C. livia) would take our results to $10.6-14.3 \mathrm{~kg}$. This overlaps with 297 the slim sculpted model based on contemporaneous accounts [13]. Including our 95\% 298 prediction intervals takes both the NHMUK Tring and South Kensington skeletons to a 299 maximum of $18.2 \mathrm{~kg}$ and $19.9 \mathrm{~kg}$ whole body masses, still considerably below the $22 \mathrm{~kg}$ 300 suggested historically [42]. In contrast, the 95\% prediction intervals of the Edinburgh 301 dodo include $22 \mathrm{~kg}$ once multiplied by 1.33 . 
303 Unlike all previous volumetric studies, our convex hulling technique does not require a

304 value for body density to be assigned from the literature. Instead we directly derive the

305 relationship between $\mathrm{M}_{\mathrm{b}}$ and $\mathrm{CH}_{\text {vol }}$ in order to avoid uncertainty regarding assigning

306 literature values, which have been shown to differ considerably across avian groups and

307 with various methodologies for estimating body density [17]. However, this does

308 implicitly rely upon the predictive equation being applied to a fossil of an extinct species

309 that is closely related to (and can therefore be assumed to share a similar body density

310 to) the modern dataset from which the predictive equation was derived. This would

311 include soft tissue density, integument density and skeleton density. In this case of

312 estimating dodo mass based on extant pigeons, we believe this assumption can be

313 upheld. In a micro-CT study of femoral and tibiotarsal mid-shaft cross-sectional

314 geometry, the dodo and solitaire have been found to possess limb bone pneumasticity

315 within the range of extant ground-dwelling and flighted species [45] for example.

316

317 Alternatively, $\mathrm{CH}_{\text {vol }}$ may be multiplied by a given value of carcass density to give a hard

318 lower limit to body mass (as carcass volume cannot be less than convex hull volume).

319 The sole literature value for intact feathered pigeon density is $648 \mathrm{~kg} / \mathrm{m}^{3}$ from

320 Hamershock et al. [46], producing hard lower bounds to estimated body mass $5.8 \mathrm{~kg}$,

$3216.3 \mathrm{~kg}$, and $7.9 \mathrm{~kg}$ for the Tring, Kensington and Edinburgh composite skeletons

322 respectively.

324 We consider the convex hulling technique to be superior to other sculpting-based

325 volumetric methods (such as manual sculpting with clay [13] or digital sculpting with 
326 non-uniform rational B-spline (NURBs) curves [20]) for the purpose of mass estimation

327 as soft tissues and hypothesized respiratory systems need not be reconstructed for

328 fossils of extinct species, and the technique is entirely repeatable. When values for

329 centre of mass (COM) and segment inertial properties are required for further

330 biomechanical analyses, NURBs may be required in order to achieve a representative

331 mass distribution across the skeleton. In such situations it is essential that soft tissue

332 reconstructions are based on quantitative comparative dissection data from relevant

333 modern species in order to minimize subjectivity in model creation. However, for the

334 sole purpose of mass estimation, convex hulling should be the preferred technique.

336 Previous authors have cautioned over the extrapolation of regression models beyond

337 the limits of the extant dataset when applied in a predictive capacity [47]. To avoid this

338 scenario, here we also apply a convex hull predictive model previously derived from

339 ratites and ground-dwelling galloanserae birds [23] to the mounted dodo specimens.

340 This results in mass estimates for the intact dodo ranging between 10.8-14.0 $\mathrm{kg}$,

341 remarkably similar to those values tentatively reconstructed by correcting the

342 eviscerated pigeon model for missing viscera content. This further strengthens the

343 argument for the reconstruction of a relatively slim dodo, and suggests extrapolation of

344 the predictive equation beyond the range of modern pigeons does not, in this instance,

345 result in implausible mass estimates.

347 Yet a predictive equation based upon cursorial ground-dwelling birds might also be

348 considered inappropriate in light of the commonly-held perception of the dodo as being 
349 poor at locomotion, i.e. non-cursorial. The issue faced when assembling a modern

350 calibration dataset on the basis of functional/behavioral similarities (as opposed to

351 phylogenetic relatedness) is the requirement to assume a particular function/behaviour

352 in a fossil species. In the case of the dodo, several 'first-hand' descriptions attest to the

353 'tameness' and 'edibility' of the bird [48, and references therein], yet very limited (and

354 contradictory) accounts exist regarding its locomotor performance. Whilst some confirm

355 the perception of dodo as fat and waddling:

356

357

"...her body is round and extremely fat, her slow pace begets that corpulence"

358

$[49, \mathrm{p} 347]$

359

360 Others suggest the dodo was capable of fast and 'jaunty' locomotion:

361

362

363

"they showed themselves to us with an abrupt stern face and wide open mouth, very jaunty and audacious of gait" $[50, \mathrm{p} 6]$

364

365

"'[they] could not fly, (because they [had] in place of the wings only small Flittige)

366 however [they] run fast" [51, p152]

367

368 In light of this confusion, a more appropriate modern calibration dataset might therefore

369 be selected on the basis of perceived evolutionary pressures (or lack thereof) to which

370 the dodo was subjected, rather than assumed locomotor ability. Yet this also proves

371 problematic, as the fates of many other recent flightless bird species that have evolved 
372 in the absence of native terrestrial predators have followed that of the dodo i.e. recent

373 extinction. Possible extant candidates are limited to the kakapo (Strigops habroptilus),

374 Galapagos cormorant (Phalacrocorax harrisi), Auckland Islands and Campbell Islands

375 teal (Anas aucklandica and Anas nesiotis) and over a dozen species of Gruiformes.

376 Given that the majority of the above species are categorized as threatened or extinct in

377 the wild [52], obtaining specimens and associated mass data is extremely challenging.

378 Therefore whilst the dodo may have differed from our modern calibration datasets in

379 being both flightless and non-cursorial, it must be recognized that a panacea for dodo

380 mass estimation is unlikely to exist, and perhaps the most appropriate recent analogues

381 are already extinct or nearing extinction.

382

383 Composite and articulated skeletons

384 The dodo specimens included in this study are composite skeletons, comprising skeletal

385 material from more than one individual and including sculpted or cast elements.

386 Therefore, our study is limited to estimating the body mass of the hypothetical animal

387 represented by each articulated skeleton, rather than a known individual. Currently

388 there exists only one near-complete dodo skeleton comprising a single individual (the

389 Thirioux dodo), upon which research is currently still continuing [53].

390

391 Whilst the use of composite skeletons should clearly be treated with caution when used

392 in biomechanical analyses, their composite nature does not entirely rule out their use,

393 particularly in the case of mass estimation. A recent large-scale macroevolutionary [54]

394 study of body size in a fossil lineage relied upon mass data derived solely from humeral 
395 and femoral circumferences of one individual specimen per species. While this

396 approach is often the only one feasible given the highly fragmentary nature of the fossil

397 record, taking one individual as being representative of an entire species leaves us

398 vulnerable to the possibility of high levels of intraspecific variation.

400 In contrast, a volumetric reconstruction based on a composite skeleton may be more

401 likely to reflect a species average by virtue of being a combination of several individuals

402 and could be less skewed by isolated robust or gracile elements. If subsequent

403 biomechanical analyses are to be carried out (such as finite element analysis on a

404 particular musculoskeletal unit), then it is important that the body mass entered into the

405 analyses is representative of that specific individual. However, for the case of volumetric

406 body mass estimation alone, it ought to be possible to derive a representative species

407 mean from a composite skeleton.

408

409 Of more concern is the frequency of missing, deformed or reconstructed material within

410 a fossil mount. Known issues with the dodo mounts included in this study include

411 missing ribs (Edinburgh skeleton), missing carpals (NHMUK South Kensington

412 skeleton), deformation of the fragile pubis (NHMUK South Kensington skeleton) or the

413 loss of the most of the ischium, pubis and caudal vertebrae (NHMUK Tring skeleton).

414 For a given object, the extent of the convex hull fitted to that object is dictated solely by

415 its geometric extremes. In many ways this is advantageous for volumetric fossil

416 reconstructions as damage occurring within the bounds of the convex hull does not

417 affect our volume estimate. However when extremities are missing (such as the caudal 
418 tip of the pubis), the shape and volume of the convex hull are strongly affected. This is

419 evident in the low percentage trunk volume of the NHMUK Tring skeleton (Figure 5)

420 compared to those of extant pigeons and other dodos.

421

422 Whilst some evidence of underdevelopment of pectoral elements and overdevelopment

423 of pelvic elements in the dodo is discernable relative to extant volant pigeons, Figure 5

424 predominantly illustrates the important contribution of trunk volume to total mass

425 estimates. The Edinburgh skeleton has a proportionally more voluminous trunk than that

426 of extant pigeons and other dodo skeletons, and therefore all other skeletal elements

427 contribute proportionally less to total $\mathrm{CH}_{\text {vol. }}$ The more voluminous trunk relative to other

428 specimens may be attributed to the anterior positioning of the sternum due to

429 constraints associated with the armature supporting the mount. The opposite is true of

430 the NHMUK Tring skeleton, in which damage to the extremities of the pelvic girdle result

431 in a reduced trunk volume. This highlights the sensitivity of volumetric reconstructions of

432 fossils of extinct species to trunk morphology, and should be a concern when working

433 with both composite and complete fossil specimens. Whilst the inclusion of cast and/or

434 sculpted material outside of the trunk may also introduce additional uncertainty into the

435 reconstruction, it is unlikely to impact heavily upon mass estimates given their relatively

436 minor contribution to overall volume (Figure 4). 


\section{Summary}

438 Here we present the first volumetric reconstruction of fossil body mass based entirely on

439 modern whole-animal CT data. The eviscerated body mass of three articulated 440 composite dodo skeletons is estimated to fall between $8.0-10.8 \mathrm{~kg}$. When accounting for

441 missing organ mass, our mean values still fall towards the lower range of previously

442 published mass estimates. As the availability and cost of CT improves, we believe this

443 non-subjective convex hull approach will become increasingly commonplace. Mass

444 estimation of extinct species from fossils relies upon two key components; a reliable

445 calibration equation derived from extant species, and an accurate reconstruction of the

446 extinct individual from its fossil. We discuss the issues surrounding the use of

447 articulated composite skeletons, and highlight the particular importance of trunk

448 morphology to volume reconstructions. We suggest future efforts should focus on

449 quantifying ribcage and sternal geometry in extant groups in order to bracket the 450 possible trunk shape in fossils of extinct species. 


\section{Acknowledgements}

452 We thank Zoller+Fröhlich $(Z+F)$ Limited for their continued support, Jennifer Anné and

453 Dr Victoria Egerton (University of Manchester), Martin Baker (University of Liverpool), 454 Malgosia Nowak-Kemp (Oxford Museum of Natural History), Judith White and Sandra 455 Chapman (Natural History Museum, London), and the reviews of Heinrich Mallison, 456 Julian Hulme and two anonymous referees. 
457

458

459

460

461

462

463

464

465

466

467

468

469

470

471

472

473

474

475

476

477

478

479

480

481

482

483

484

485

486

487

\section{References}

1. Schmidt-Nielsen K. Scaling: Why is animal size so important? Cambridge: Cambridge University Press; 1984.

2. Turner AH, Pol D, Clarke JA, Erickson GM, Norell MA. A basal dromaeosaurid and size evolution preceding avian flight. Science (80- ). 2007;317: 1378-1381. doi:10.1126/science.1144066

3. Boyer AG. Extinction patterns in the avifauna of the Hawaiian islands. Divers Distrib. 2008;14: 509-517. doi:10.1111/j.1472-4642.2007.00459.x

4. Hone DWE, Dyke GJ, Haden M, Benton MJ. Body size evolution in Mesozoic birds. J Evol Biol. 2008;21: 618-624. doi:10.1111/j.1420-9101.2007.01483.x

5. Butler RJ, Goswami A. Body size evolution in Mesozoic birds: Little evidence for Cope's rule. J Evol Biol. 2008;21: 1673-1682. doi:10.1111/j.14209101.2008.01594.x

6. Brassey CA, Holdaway RN, Packham AG, Anne J, Manning PL, Sellers WI. More Than One Way of Being a Moa: Differences in Leg Bone Robustness Map Divergent Evolutionary Trajectories in Dinornithidae and Emeidae (Dinornithiformes). PLoS One. 2013;8: e82668. doi:10.1371/journal.pone.0082668

7. Campione NE, Evans DC. A universal scaling relationship between body mass and proximal limb bone dimensions in quadrupedal terrestrial tetrapods. BMC Biol. 2012;10: 60.

8. Field DJ, Lynner C, Brown C, Darroch SAF. Skeletal Correlates for Body Mass Estimation in Modern and Fossil Flying Birds. PLoS One. 2013;8: e82000. doi:10.1371/journal.pone.0082000

9. Cubo J, Arthur W. Patterns of correlated character evolution in flightless birds: a phylogenetic approach. Evol Ecol. 2000;14: 693-702.

10. Linnaeus $\mathrm{C}$. Systema naturae per regna tria naturae: secundum classes, ordines, genera, species, cum characteribus, differentiis, synonymis, locis. Stockholm: Impensis Direct; 1758.

11. Hume JP. The history of the Dodo Raphus cucullatus and the penguin of Mauritius. Hist Biol. 2006;18: 65-89. 
488

489

490

491

492

493

494

495

496

497

498

499

500

501

502

503

504

505

506

507

508

509

510

511

512

513

514

515

516

517

518

519

520

521

12. Livezey BC. An ecomorphological review of the dodo (Raphus cucullatus) and solitaire (Pezophaps solitaria), flightless Columbiformes of the Mascarene Islands. J Zool. 1993;230: 247-292.

13. Kitchener AC. The external appearance of the dodo, Raphus cucullatus. Arch Nat Hist. 1993;20: 279-301.

14. Angst D, Buffetaut E, Abourachid A. The end of the fat dodo? A new mass estimate for Raphus cucullatus. Naturwissenschaften. 2011;98: 233-236.

15. Louchart A, Mourer-Chauviré $C$. The dodo was not so slim : leg dimensions and scaling to body mass. Naturwissenschaften. 2011;98: 357-358.

doi:10.1007/s00114-011-0771-6

16. Angst D, Buffetaut E, Abourachid A. In defence of the slim dodo: a reply to Louchart and Mourer-Chauviré. Naturwissenschaften. 2011;98: 359-360. doi:10.1007/s00114-011-0772-5

17. Seebacher F. A new method to calculate allometric length-mass relationships of dinosaurs. J Vertebr Paleontol. 2001;21: 51-60.

18. Hutchinson JR, Ng-Thow-Hing V, Anderson FC. A 3D interactive method for estimating body segmental parameters in animals: Application to the turning and running performance of Tyrannosaurus rex. J Theor Biol. 2007;246: 660-680.

19. Gunga HC, Suthau T, Bellmann A, Stoinski S, Friedrich A, Trippel T, et al. A new body mass estimation of Brachiosaurus brancai Janensch, 1914 mounted and exhibited at the Museum of Natural History (Berlin, Germany). Foss Rec. 2008;11: 33-38. doi:10.1002/mmng.200700011

20. Bates KT, Manning PL, Hodgetts D, Sellers WI. Estimating mass properties of dinosaurs using laser imaging and 3D computer modelling. PLoS One. 2009;4: e4532.

21. Allen V, Paxton H, Hutchinson JR. Variation in Center of Mass Estimates for Extant Sauropsids and its Importance for Reconstructing Inertial Properties of Extinct Archosaurs. Anat Rec. 2009;292: 1442-1461.

22. Sellers WI, Hepworth-Bell J, Falkingham PL, Bates KT, Brassey CA, Egerton VM, et al. Minimum convex hull mass estimations of complete mounted skeletons. Biol Lett. 2012;8: 842-845.

23. Brassey CA, Sellers WI. Scaling of convex hull volume to body mass in modern primates, non-primate mammals and birds. PLoS One. 2014;9: e91691. doi:10.1371/journal.pone.0091691 
522 24. Swainson W. On the Characters and Natural Affinities of Serveral New Birds from

523

524

525

526

527

528

529

530

531

532

533

534

535

536

537

538

539

540

541

542

543

544

545

546

547

548

549

550

551

552

553

Australasia: Including Some Observations on the Columbidæ. Zool J. 1825;1:

463-484.

25. Fraser L. A description of a new species of Crowned Pigeon from New Guinea. Proc Zool Soc London. 1844;12: 136.

26. Shapiro B, Sibthorpe D, Rambaut A, Austin J, Wragg GM, Bininda-Emonds ORP, et al. Flight of the dodo. Science. 2002;295: 1683.

doi:10.1126/science.295.5560.1683

27. CIBC. Seg3D: Volumetric Image Segmentation and Visualization. Scientific Computing and Imaging Institute (SCl). 2014.

28. Barber CB, Dobkin DP, Huhdanpaa HT. The Quickhull algorithm for convex hulls. ACM Trans Math Softw. 1996;22: 469-483.

29. Smith RJ. Use and misuse of the reduced major axis for line-fitting. Am J Phys Anthropol. 2009;140: 476-486.

30. Lavin SR, Karasov WH, Ives AR, Middleton KM, Garland Jr T. Morphometrics of the Avian Small Intestine Compared with That of Nonflying Mammals: A Phylogenetic Approach. Physiol Biochem Zool. 2008;81: 526-550.

31. Paradis E, Claude J, Strimmer K. APE: analyses of phylogenetics and evolution in R. Bioinformatics. 2004;20: 289-290.

32. Jetz W, Thomas GH, Joy JB, Hartmann K, Mooers AO. The global diversity of birds in space and tim. Nature. 2012;491: 444-448. doi:10.1038/nature11631

33. Hackett SJ, Kimball RT, Reddy S, Bowie RCK, Braun EL, Braun MJ, et al. A phylogenomic study of birds reveals their evolutionary history. Science (80- ). AAAS; 2008;320: 1763.

34. Falkingham PL. Acquisition of high resolution three-dimensional models using free, open-source, photogrammetric software. Palaeontol Electron. 2012;15: 1T.

35. Mallison $\mathrm{H}$, Wings $\mathrm{O}$. Photogrammetry in Paleontology - A Practical Guide. J Paleontol Tech. 2014;12: 1-31.

36. Wu C. VisualSFM: A visual structure from motion system. [Internet]. 2011.

37. Brassey C, Gardiner J. An advanced shape-fitting algorithm applied to the vertebrate skeleton: improving volumetric mass estimates. $R$ Soc Open Sci.

38. Dunning J. CRC handbook of avian body masses. Boca Raton: CRC Press; 1992. 
554 39. Ibrahim $\mathrm{T}$, Bashrat O. Carcass characteristics of pigeons reared in Bauchi Metropolis, north eastern Nigeria. Anim Prod Res Adv. 2009;5.

556

557

558

559

560

561

562

563

564

565

566

567

568

569

570

571

572

573

574

575

576

577

578

579

580

581

582

583

584

585

586

587

588

40. Omojola AB, Isa MA, Jibir M, S ABTG, Kassim OR, Omotoso AB, et al. Carcass Characteristics and Meat Attributes of Pigeon (Columbia livia) as Influenced by Strain and Sex. J Anim Sci Adv. 2012;2: 475-480.

41. Roth VL. Insular dwarf elephants: a case study in body mass estimation and ecological inferenc. In: Damuth J, MacFadden B, editors. Body size in mammalian paleobiology: Estimates and biological implications. Cambridge: Cambridge University Press; 1990. pp. 151-180.

42. Herbert T. A relation of some yeares' travaile, begunne Anno 1626, into Afrique and the greater Asia, especially the territories of the Persian Monarchie, and some parts of the Oriental Indies and Isles adiacent. London: W Stansby \& J Bloome; 1634.

43. Kirkwood JK, Duignan PJ, Kember NF, Bennett PM, Price DJ. The growth rate of the tarsometatarsus bone in birds. J Zool. 1989;217: 403-416. doi:10.1111/j.1469-7998.1989.tb02498.x

44. Campbell KE, Marcus $\mathrm{L}$. The relationship of hindlimb bone dimensions to body weight in birds. In: Campbell KE, editor. Papers in avian paleontology honouring Pierce Brodkorb Science Series 39. Los Angeles: Natural History Museum of Los Angeles; 1992. pp. 395-411.

45. Brassey CA, Kitchener AC, Withers PJ, Manning PL, Sellers WI. The Role of Cross-Sectional Geometry, Curvature, and Limb Posture in Maintaining Equal Safety Factors: A Computed Tomography Study. Anat Rec. 2013;296: 395-413.

46. Hamershock DM, Seamans TW, Bernhard GE. Determination of body density for twelve bird species. Flight Dynamics Directorate, Wright Laboratory. Flight Dynamics Directorate, Wright Laboratory; 1993.

47. Henderson D. Burly Gaits: Centers of mass, stability, and the trackways of sauropod dinosaurs. J Vertebr Paleontol. The Society of Vertebrate Paleontology; 2006;26: 907-921.

48. Parish JC. The dodo and the solitaire: A natural history. Farlow JO, editor. Bloomington: Indiana University Press; 2013.

49. Herbert T. A relation of some yeares' travaile, begunne Anno 1626, into Afrique and the greater Asia, especially the territories of the Persian Monarchie, and some parts of the Oriental Indies and Isles adiacent. Revised and enlarged by the author. London: W Stansby \& J Bloome; 1638. 
589 50. Servaas van Rooijen A. Hongersnood in Suratta. Navors. 1887;4: 4-8.

590 51. Olearius A. Orientalische Reise-Beschreibung: Jurgen Andersen aus SchleBwig, Der Annon Christi 1644 auB gezogen, und 1650 wieder kommen. Und Volquard

593 52. IUCN. IUCN Red List of Threatened Species. 2013.

53. Randall A, Pepe A, Yamartino K, Kimelblatt A, Claeesens L. How fat was the Dodo? The first mass estimate from digital body reconstruction based on a complete skeleton of Raphus cucullatus. Society of Vertebrate Paleontology Annual Meeting 2014, Berlin Poster Abstract. 2014.

54. Benson RBJ, Campione NE, Carrano MT, Mannion PD, Sullivan C, Upchurch P, et al. Rates of dinosaur body mass evolution indicate 170 million years of sustained ecological innovation on the avian stem lineage. PLoS Biol. 2014;12:

601

602 603

55. Rosset A, Spadola L, Ratib O. OsiriX: an open-source software for navigating in multidimensional DICOM images. J Digit Imaging. 2004;17: 205-216. 
604 Figure 1. Example of the convex hulling process applied to the CT scanned carcass of a 605 Victoria crowned pigeon (Goura victoria) from which the skeleton has been segmented.

606 A and C, skeleton in dorsal and lateral view respectively and; B and D, corresponding

607 convex hulls fitted to the functional units of the skeleton. Note convex hulls fitted to the

608 feet in 1D are strongly influenced by the positioning of the toes (see in text for 609 discussion).

610 Figure 2. OLS regression results. Body mass $(\mathrm{g})$ against convex hull volume $\left(\mathrm{mm}^{3}\right)$. For

611 slope equations see Table 2. Filled circles and solid line, eviscerated carcasses;

612 crosses and dashed line, intact carcasses; dot-dash line, combined sample.

613 Figure 3. A, Photogrammetry model of the Tring dodo skeleton (S/1988.50.1); B, 614 volumetric convex hulls fitted around the skeleton.

615 Figure 4. The distribution of segment $\mathrm{CH}_{\text {vol }}$ as a proportion of total $\mathrm{CH}_{\text {vol }}$ within the 616 convex hulled skeletons of extant pigeons and articulated dodo skeletons. Mean values 617 are illustrated for extant pigeons. Error bars represent $95 \%$ confidence intervals of the 618 mean. The underdevelopment of the pectoral girdle (humerus, radius and ulna and 619 carpometacarpals) in dodo relative to extant pigeons is particularly striking.

620 Figure 5. Volumetric renderings of a rock dove (Columba livia, $A-B$ ) and collared dove 621 (Streptopelia decaocto, C-D) generated from CT scans. A and C illustrate the outer soft 622 tissue contours of the carcass, while B and D illustrate the position of the gizzard and 623 associated gizzard contents. There is considerable variation in the quantity and size of 
624 gizzard stones between intact pigeon specimens within the dataset. Renderings were 625 generated in OsiriX [55] 


\section{Table $\mathbf{1}$ (on next page)}

Specimen list of modern pigeons

Table 1. Specimen list of modern pigeons sourced from National Museums Scotland,

Edinburgh. $\mathrm{CH}_{\text {vol }}$, minimum convex hull volume of the skeleton; $\mathrm{CH}_{\mathrm{vol}}$ - feet, minimum convex hull volume minus the volume of the feet. * indicates specimens were sourced from the University of Manchester. All other specimens were loaned from National Museums Scotland, Edinburgh. 
1

\begin{tabular}{|c|c|c|c|c|c|}
\hline Species name & Common name & Body mass (g) & Preparation & $\mathrm{CH}_{\text {vol }}\left(\mathrm{mm}^{3}\right)$ & $\mathrm{CH}_{\text {vol }}-$ feet $\left(\mathrm{mm}^{3}\right)$ \\
\hline Goura victoria & Victoria crowned pigeon & $\overline{1951}$ & Eviscerated & 1487180 & 1436777 \\
\hline Streptopelia decaocto* & Collared dove & 201 & Intact & 203875 & 196791 \\
\hline Columba livia & Rock dove & 290 & Intact & 115945 & 113074 \\
\hline Columba palumbus* & Wood pigeon & 305 & Intact & 337993 & 328279 \\
\hline Ducula bicolor & Pied imperial pigeon & 450 & Eviscerated & 337377 & 329220 \\
\hline Petrophassa rufipennis & Chestnut-quilled rock pigeon & 314 & Eviscerated & 303511 & 286104 \\
\hline Otidiphaps nobilis & Pheasant pigeon & 401 & Eviscerated & 344368 & 329238 \\
\hline Nesoenas mayeri & Pink pigeon & 200 & Eviscerated & 197171 & 185981 \\
\hline Ducula sp. & Imperial pigeon & 336 & Eviscerated & 314985 & 305344 \\
\hline Caloenas nicobarica & Nicobar pigeon & 539 & Eviscerated & 383736 & 367753 \\
\hline Phaps chalcoptera & Common bronze-winged pigeon & 249 & Intact & 213953 & 208942 \\
\hline Ducula aenea & Green imperial pigeon & 483 & Intact & 348268 & 336968 \\
\hline Columba guinea & Speckled pigeon & 158 & Intact & 105156 & 102041 \\
\hline Zenaida graysoni & Socorro dove & 176 & Eviscerated & 105776 & 102441 \\
\hline
\end{tabular}




\begin{tabular}{|c|c|c|c|c|c|}
\hline Gallicolumba sp. & Bleeding heart dove & 215 & Eviscerated & 163764 & 152136 \\
\hline Phapitreron leucotis & White-eared brown dove & 107 & Eviscerated & 69424 & 67088 \\
\hline Ptilinopus sp. & Fruit dove & 71 & Eviscerated & 47816 & 46635 \\
\hline Ptilinopus superbus & Superb fruit dove & 137 & Eviscerated & 77882 & 74691 \\
\hline$\underline{\text { Treron vernans }}$ & Pink-necked green pigeon & 167 & Eviscerated & 104991 & 101984 \\
\hline Ocyphaps lophotes & Crested pigeon & 107 & Intact & 67451 & 64011 \\
\hline
\end{tabular}

2 Table 1. Specimen list of modern pigeons sourced from National Museums Scotland, Edinburgh. $\mathrm{CH}_{\mathrm{vol}}$, minimum convex

3 hull volume of the skeleton; $\mathrm{CH}_{\text {vol }}$ - feet, minimum convex hull volume minus the volume of the feet. * indicates specimens

4 were sourced from the University of Manchester. All other specimens were loaned from National Museums Scotland,

5 Edinburgh.

6

7

8

9 


\section{Table 2 (on next page)}

Details of mass prediction equations

Ordinary least squares regressions of $\log _{10}$ body mass $(\mathrm{g})$ against $\log _{10}$ convex hull volume $\left(\mathrm{CH}_{\text {vol, }} \mathrm{mm}^{3}\right) . \pm 95 \%, 95 \%$ confidence intervals of the intercept and slope; MSE, mean square error of the regression; AIC, Akaike Information Criterion calculated for Ordinary Least Squares (OLS) and Phylogenetically Generalised Least Squares (PGLS). Ground-dwelling refers to the predictive equation based upon ratites and fowl derived from [23] . 


\begin{tabular}{lllllllll}
\hline Model & $a$ & $a( \pm 95 \%)$ & $b$ & $b( \pm 95 \%)$ & $r^{2}$ & $p$ & AIC ${ }_{\text {OLS }}$ & AIC $\mathrm{PGLS}$ \\
\hline Eviscerated & -2.31 & $-2.90--1.72$ & 0.89 & $0.78-1.00$ & 0.97 & $<0.001$ & -28.42 & -20.97 \\
- minus feet & -2.31 & $-2.87--1.74$ & 0.90 & $0.79-1.00$ & 0.97 & $<0.001$ & -29.38 & -22.22 \\
Intact & -1.08 & $-3.69--1.53$ & 0.66 & $0.16-1.16$ & 0.70 & 0.019 & -5.29 & -10.15 \\
- minus feet & -1.06 & $-3.62--1.50$ & 0.66 & $0.17-1.15$ & 0.70 & 0.018 & -5.41 & -10.41 \\
Combined & -2.08 & $-2.75--1.42$ & 0.85 & $0.72-0.98$ & 0.92 & $<0.001$ & -34.42 & -26.64 \\
- minus feet & -2.08 & $-2.73--1.42$ & 0.85 & $0.73-0.98$ & 0.92 & $<0.001$ & -34.94 & -27.39 \\
Ground-dwelling & -1.65 & $-2.52--0.77$ & 0.82 & $0.69-0.95$ & 0.97 & $<0.001$ & &
\end{tabular}

1 Table 2. Ordinary least squares regressions of $\log _{10}$ body mass $(\mathrm{g})$ against $\log _{10}$ convex hull volume $\left(\mathrm{CH}_{\mathrm{vol}}, \mathrm{mm}^{3}\right)$. $\pm 95 \%$,

$295 \%$ confidence intervals of the intercept and slope; MSE, mean square error of the regression; AIC, Akaike Information

3 Criterion calculated for Ordinary Least Squares (OLS) and Phylogenetically Generalised Least Squares (PGLS). Ground-

4 dwelling refers to the predictive equation based upon ratites and fowl derived from [23]. 


\section{Table 3(on next page)}

Predicted body mass of the dodo

$M_{\mathrm{b}}$ estimated using 'eviscerated' equation minus feet (Table 2 ) and applying correction factor $e(M S E / 2)$ to account for back-transformation of a log-linear model into a power function, where MSE is the mean square error reported in Table 2. 95\% $\mathrm{PI}, 95 \%$ prediction intervals. Ground-dwelling refers to the predictive equation based upon ratites and fowl derived from [23] * *Calculated on the basis of dodo $\mathrm{CH}_{\text {vol }}$ including feet, as per the modern grounddwelling birds. 


\begin{tabular}{|c|c|c|c|c|c|c|c|}
\hline Model & $\begin{array}{l}\text { Accession } \\
\text { number }\end{array}$ & $\begin{array}{l}\mathrm{CH}_{\mathrm{vol}} \\
\left(\mathrm{mm}^{3}\right)\end{array}$ & $\begin{array}{l}\mathrm{CH}_{\mathrm{vol}}-\text { feet } \\
\left(\mathrm{mm}^{3}\right)\end{array}$ & $\begin{array}{l}\text { Eviscerated } \\
M_{\mathrm{b}}(\mathrm{g})\end{array}$ & $95 \% \mathrm{PI}(\mathrm{g})$ & $\begin{array}{l}\text { Ground-dwelling } \\
M_{\mathrm{b}}(\mathrm{g})^{*}\end{array}$ & $95 \% \mathrm{PI}(\mathrm{g})$ \\
\hline NHMUK Tring dodo & S/1988.50.1 & 8942820 & 8445134 & 7980 & 4653- 13685 & 10869 & $5737-20593$ \\
\hline NHMUK Kensington dodo & NHM A.9040 & 9730367 & 9283795 & 8687 & $5027-15011$ & 11646 & $6141-22084$ \\
\hline Edinburgh dodo & NMS.Z.1993.13 & 12147000 & 11787000 & 10760 & 6106-18961 & 13960 & $7338-26560$ \\
\hline
\end{tabular}

2 Table 3. $M_{\mathrm{b}}$ estimated using 'eviscerated' equation minus feet (Table 2) and applying correction factor e(MSE/2) to

3 account for back-transformation of a log-linear model into a power function, where MSE is the mean square error reported

4 in Table 2. 95\%PI, 95\% prediction intervals. Ground-dwelling refers to the predictive equation based upon ratites and fowl

5 derived from [23]. *Calculated on the basis of dodo $\mathrm{CH}_{\mathrm{vol}}$ including feet, as per the modern ground-dwelling birds. 
1

Convex hulling process

Example of the convex hulling process applied to the CT scanned carcass of a Victoria crowned pigeon (Goura victoria) from which the skeleton has been segmented. A and C, skeleton in dorsal and lateral view respectively and; B and D, corresponding convex hulls fitted to the functional units of the skeleton. Note convex hulls fitted to the feet in 1D are strongly influenced by the positioning of the toes (see in text for discussion).

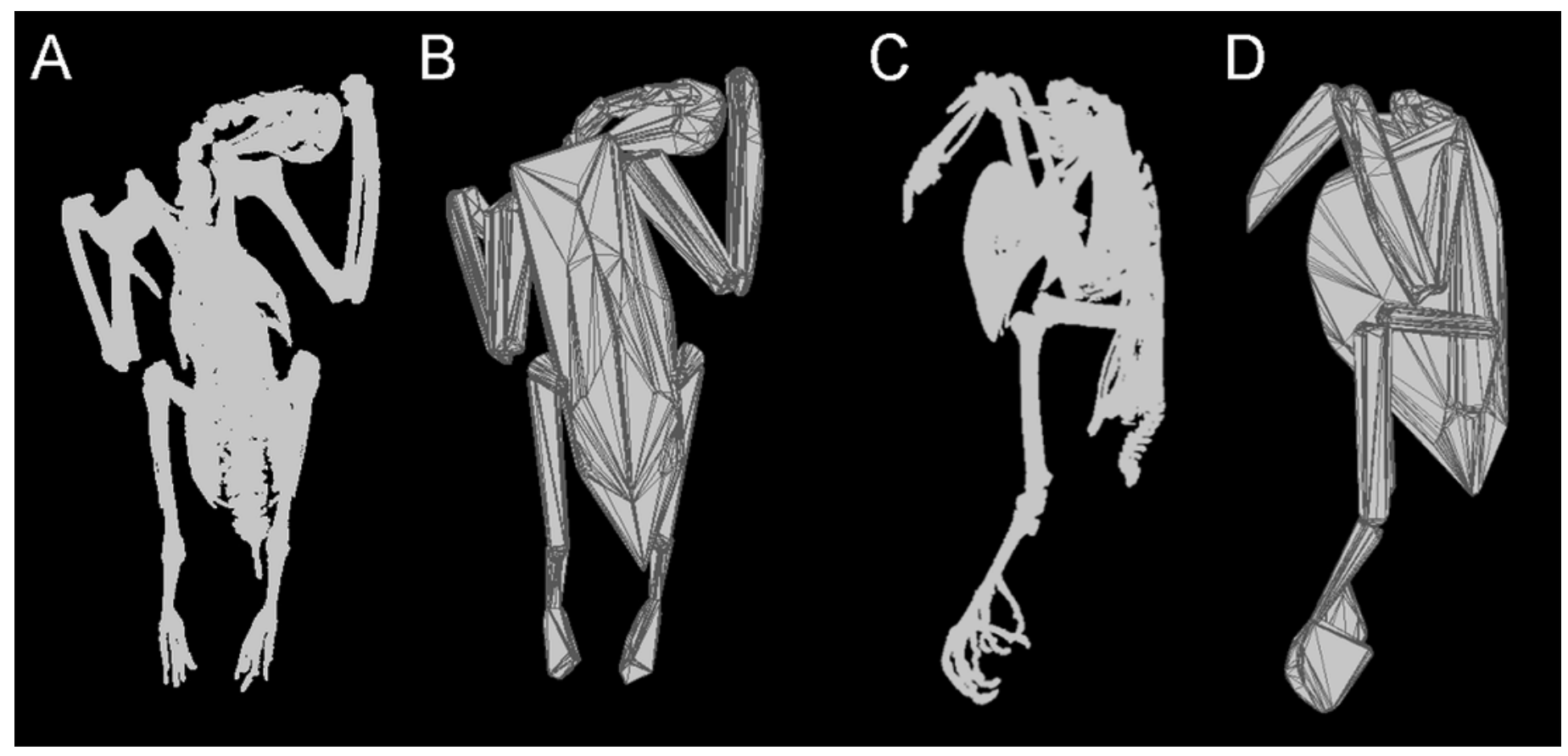


2

Convex hull predictive model

OLS regression results. Body mass $(\mathrm{g})$ against convex hull volume $\left(\mathrm{mm}^{3}\right)$. For slope equations see Table 2. Filled circles and solid line, eviscerated carcasses; crosses and dashed line, intact carcasses; dot-dash line, combined sample.

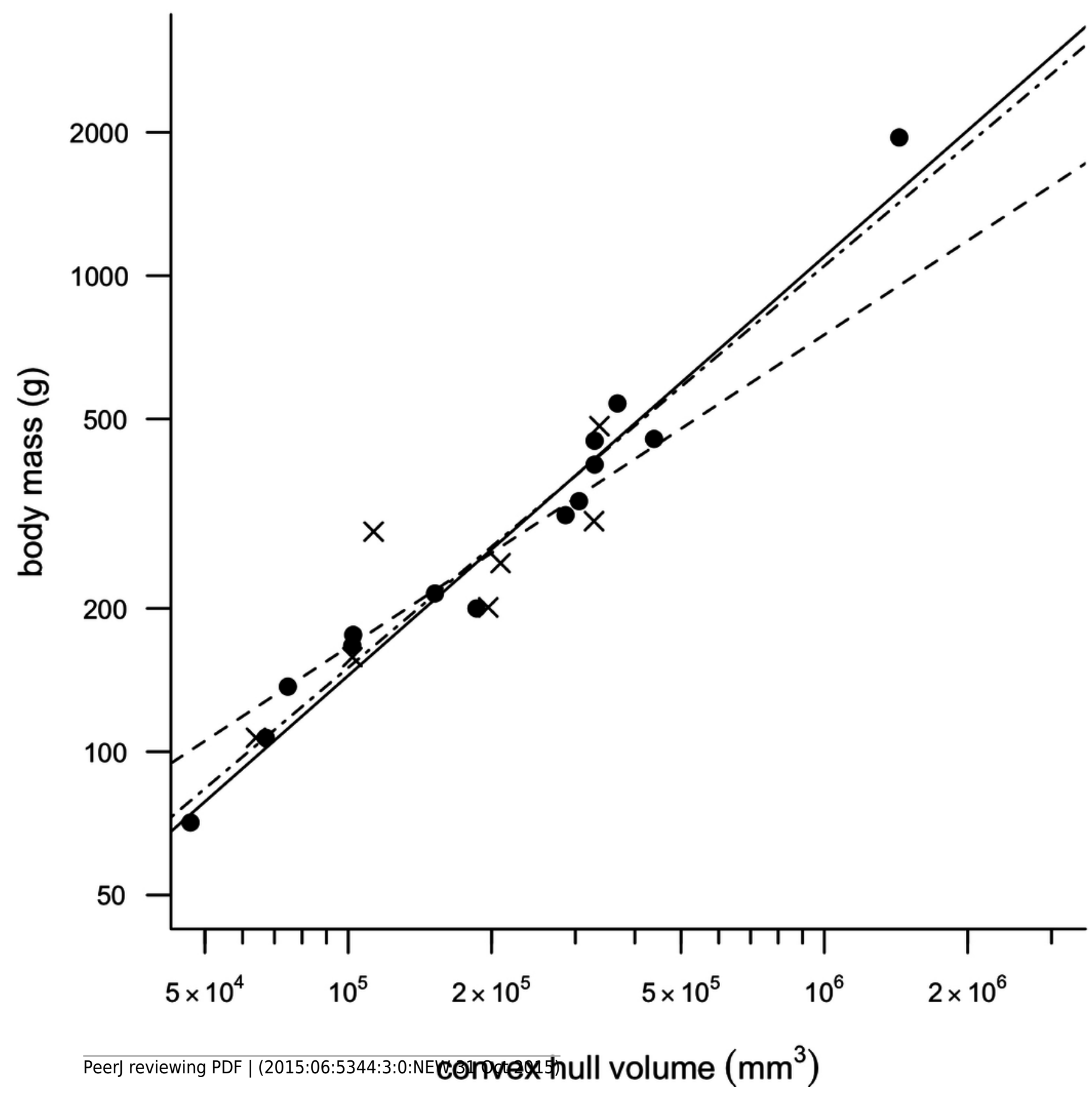




\section{PeerJ}

3

Convex hull model of Tring dodo

A, Photogrammetry model of the Tring dodo skeleton (S/1988.50.1); B, volumetric convex hulls fitted around the skeleton.

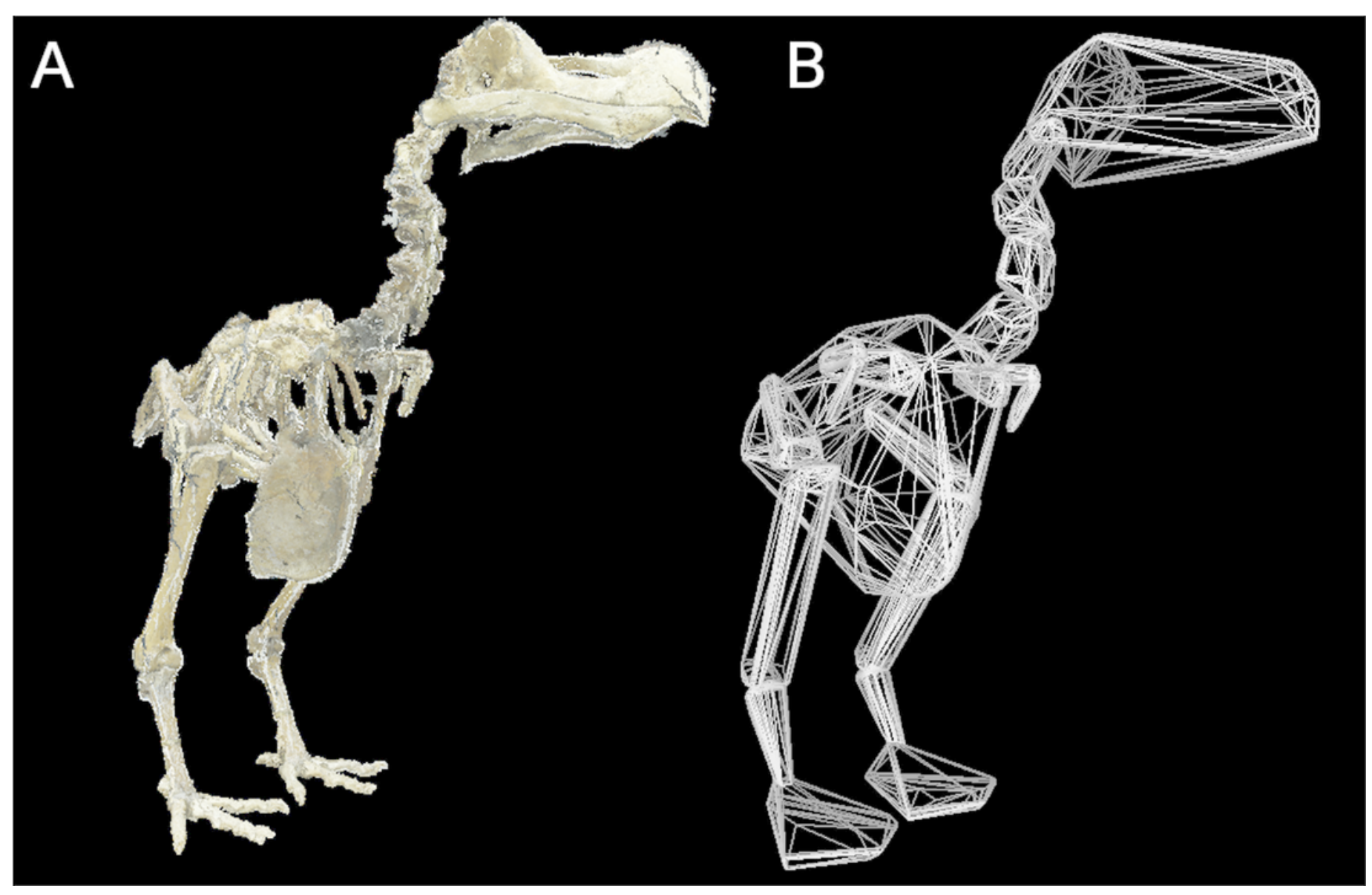


4

Distribution of convex hull volume around the pigeon skeleton

The distribution of segment $\mathrm{CH}_{\mathrm{vol}}$ as a proportion of total $\mathrm{CH}_{\text {vol }}$ within the convex hulled skeletons of extant pigeons and articulated dodo skeletons. Mean values are illustrated for extant pigeons. Error bars represent 95\% confidence intervals of the mean. The underdevelopment of the pectoral girdle (humerus, radius and ulna and carpometacarpals) in dodo relative to extant pigeons is particularly striking.
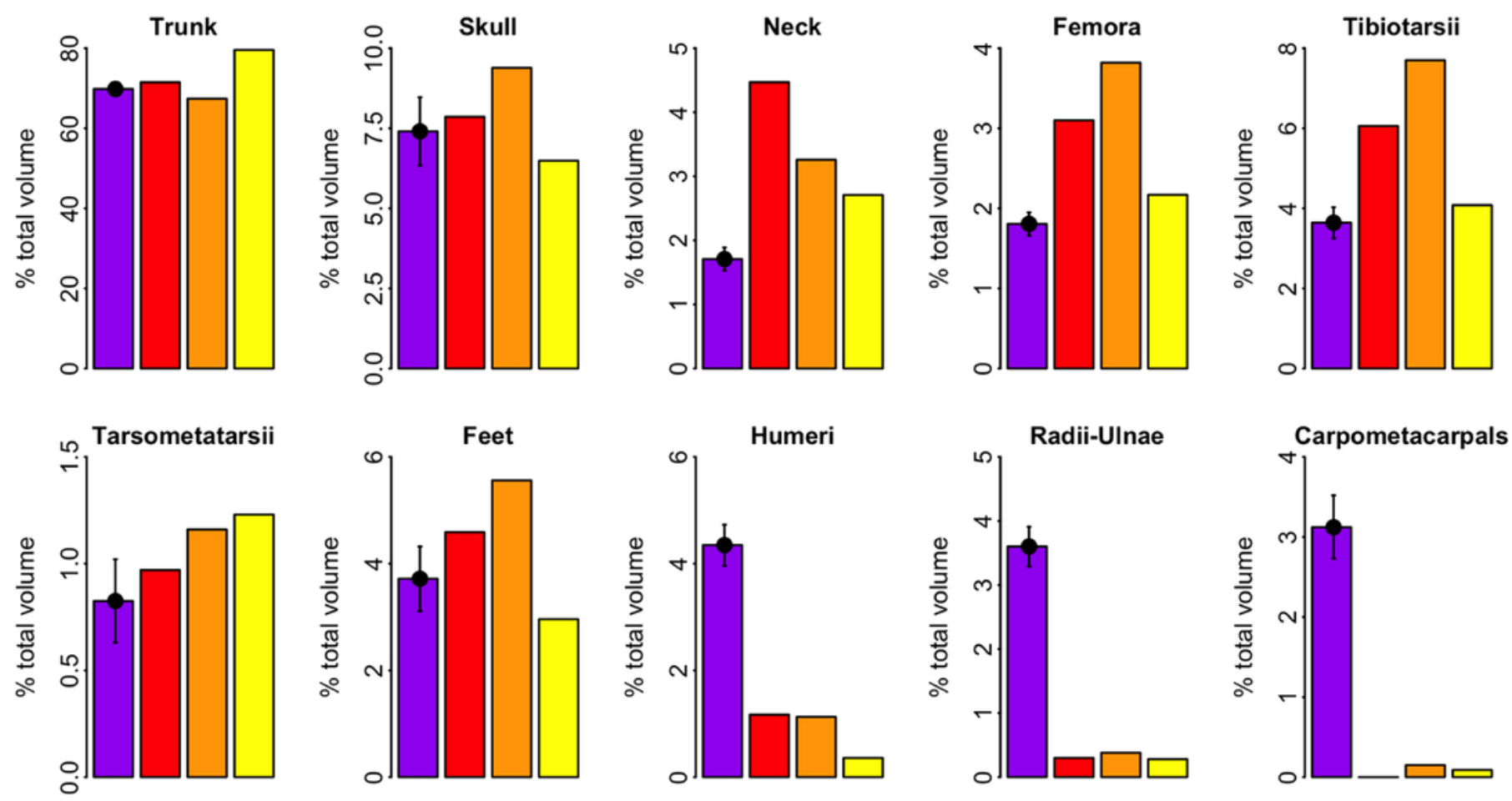

Extant pigeon $\mathrm{CT}$

NHM South Ken.

NHM Tring

Edinburgh 


\section{5}

Volume renderings of modern pigeon $\mathrm{CT}$ data

Volumetric renderings of a rock dove (Columba livia, $A-B$ ) and collared dove (Streptopelia decaocto, $C-D$ ) generated from CT scans. A and C illustrate the outer soft tissue contours of the carcass, while $B$ and $D$ illustrate the position of the gizzard and associated gizzard contents. There is considerable variation in the quantity and size of gizzard stones between intact pigeon specimens within the dataset. Renderings were generated in OsiriX [50]

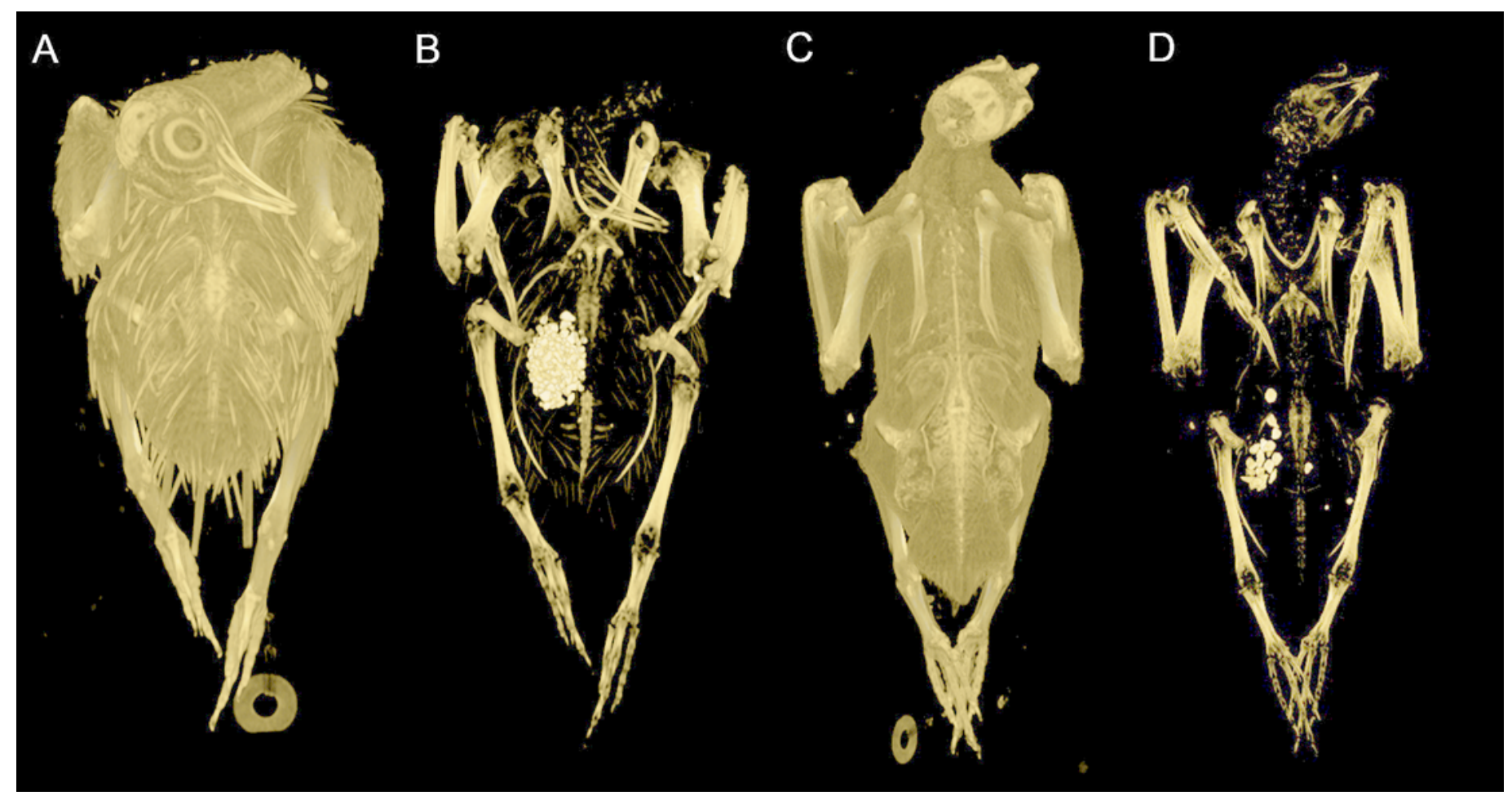

